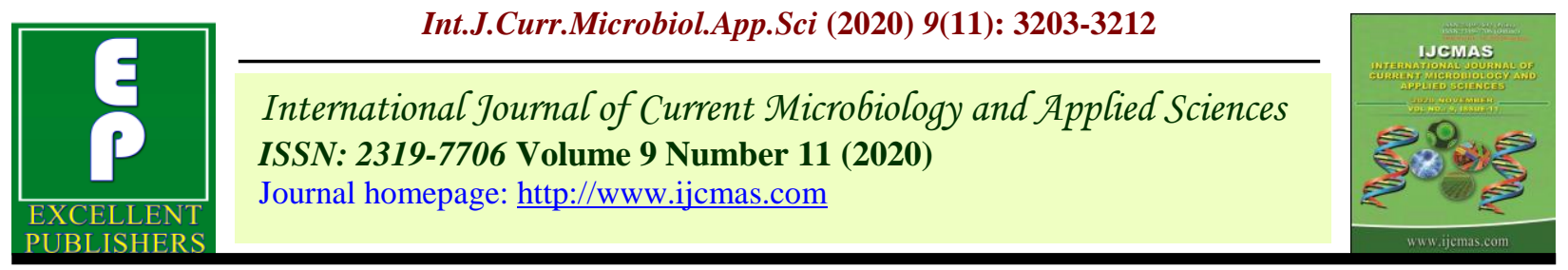

Original Research Article

https://doi.org/10.20546/ijcmas.2020.911.386

\title{
Evaluation of Cotton Genotypes for Drought Tolerance using PEG-6000 Water Stress by Slanting Glass Plate Technique
}

\author{
K. N. Pawar" and V. B. Veena \\ Agriculture Research Station, Dharwad farm, UAS, Dharwad, Karnataka, India \\ *Corresponding author
}

\begin{abstract}
A B S T R A C T
\end{abstract}

\begin{tabular}{l} 
K e y w or d s \\
Cotton, \\
Germination, \\
Osmotic potential, \\
PEG-6000, \\
Seddling vigour \\
\hline Article Info \\
\hline $\begin{array}{l}\text { Accepted: } \\
22 \text { October } 2020 \\
\text { Available Online: } \\
\text { 10 November } 2020\end{array}$ \\
\hline
\end{tabular}

A laboratory experiment was conducted during 2020 at Agriculture Research Station, Crop Physiology division, Dharwad, to screen the cotton verities to water stress condition for Seed germination and Seedling growth. The study consists of eight cotton varieties viz., PA-810, CDP-1652, DB-1602, SCS-1061, DLSa-17, Sahana, ARBH-813 and Suvin were evaluated for drought tolerance using PEG-6000 water stress at germination stage. The genotypes were subjected to different osmotic potentials $0 \%, 5 \%, 10 \%, 20 \%$ and $25 \%$ (0.0MPa,-0.05 MPa,-0.148 MPa,-0.295 MPa,-0.491 MPa,-0.735 $\mathrm{MPa}$ respectively) by slanting glass plate technique. The genotypes were evaluated for percent seed germination and seedling vigour traits at $12^{\text {th }}$ and $18^{\text {th }}$ day showed maximum concentration of PEG6000 for the germination is $20 \%$ and shoot growth was inhibited at 20\% PEG-6000 in all genotypes. As the concentration increases there was an increase in root to shoot ratio. In conclusion the genotypes which found tolerant to the increased osmotic potential were PA810, CPD-1652 DB-1602 and DLSa-17 whereas SCS-1061, Sahana, ARBH-813 and Suvin were found as drought sensitive genotypes.

\section{Introduction}

Cotton is one of the most important fiber and cash crop of India and plays a dominant role in the industrial and agricultural economy of the country. It provides the basic raw material (cotton fibre) to cotton textile industry. Cotton in India provides direct livelihood to 6 million farmers and about 40 -50 million people are employed in cotton trade and its processing (FICCI, 2012). According to the Cotton corporation of India estimates, In India cotton is grown in an area of 125.84 lakh hectare, with production of 360 lakh bales of cotton and productivity of $486 \mathrm{~kg}$ per hectare (CCI, 2019-20).

The major reasons for low yield in India are biotic, abiotic, and technological problems. One of the major abiotic stresses affecting plant productivity is water stress resulting through drought which limits crop growth and productivity. Water availability and quality affect the growth and physiological processes of all plants since water is the primary component of actively growing plants ranging from 70-90\% of plant fresh mass. Due to its predominant role in plant nutrient transport, 
chemical and enzymatic reactions, cell expansion and transpiration, water stresses result in anatomical and morphological alterations as well as changes in physiological and biochemical processes affecting functions of the plants. Plant water deficits depend both on the supply of water to the soil and the evaporative demand of the atmosphere. In general, plant water stress is defined as the condition where a plant's water potential and turgor are decreased enough to inhibit normal plant function. The effect of water stress depends on the severity and duration of the stress, the growth stage at which stress is imposed and the genotype of the plant. The effect of water stress on growth, yield components and quality characters are widely different and severe. The turgor loss is the first effect of water stress that influences cell growth rate and its final volume. Cotton is one of the most important economic crops in world. It is grown in both dry land and irrigated areas. Among the abiotic stresses, water stress is recognized as the most devasting cause which limits the fiber yield and lint quality in cotton production. The flowering and boll development stage are the critical stages of irrigation that determines the yield in cotton. Short-duration water stress occurring during this stage significantly affects various physiological and biochemical characters in cotton plants, such as leaf expansion, photosynthesis, carbon and nitrogen metabolism and antioxidant metabolism.

The PEG was first time used as an inducer and identifier to screen and select drought resistant tobacco cell lines. Chinese researchers used to do cotton drought evaluation and identification by repeated drought induction method. It is still in the experimental stage to use PEG solution for the identification. PEG-6000 was used to establish a rapid and effective cotton-drought tolerance evaluation system for selection and breeding of the drought-tolerant cotton genotypes (Michel et al., 1973).Earlier germination studies have been carried out with aqueous solutions of polyethyleneglycol6000 (PEG-6000) and mannitol (Fanti et al., 2004). Laboratory assays simulating water stress circumstances have aided researchers for the identification of cultivars with an elevated level of resistance to such adverse conditions in other crops, such as maize (Tonin et al., 2000). Water stress induced by PEG, leads to decrease in the germination index and the morphological development of organs from young cotton plants and also reported that water absorption, retention and biomass gain were affected by water stress (Fernandez et al., 1998).

Performance of cotton genotypes for drought tolerance using PEG water stress at germination, bud-stage, cotyledon stage and real-leaf stage revealed that at $17 \%$ PEG-6000 treatment the seedlings growth rate showed inhibition. Physiological quality of cotton cultivar seeds were evaluated in laboratory by the simulation of water potentials with polyethyleneglycol-6000 (0.0; -0.2; -0.4; -0.6; $-0.8 ;-1.0 \mathrm{MPa})$, at $25{ }^{\circ} \mathrm{C}$ using germitest paper as substrate. The effect of water stress on seed viability and on plantlet vigor was severe at potentials below $-0.4 \mathrm{MPa}$. Differential viability and vigor between cultivars were observed under the water stress levels with polyethyleneglycol-6000 (Carlos et al., 2011). Evaluation of the germination capacity of seeds is one of the most common methods used to determine the tolerance of plants to abiotic stresses (Larcher et al., 2000)

PEG has been used to establish a rapid and effective cotton-drought tolerance evaluation system for selection and breeding of the drought tolerant resources (Yu, X.G et al., 1999). That osmotic adjustment using PEG6000 in cotton could be used to evaluate the drought tolerance of cotton. This method is 
simple, fast and easily operated, could be used to evaluate the drought tolerance of cotton (Babu et al., 2014). Hence in this direction by knowing the economic importance of cotton all over the India and of the factors which interfere in its cotton seed germination, the present study aimed to evaluate the effect of drought stress on the viability and vigor of cotton cultivar seeds in germination phase. Hence the objective of this paper is to evaluation and identification of eight Indian cotton genotypes for drought tolerance using PEG-6000 as an osmotic stress inducer by slanting glass plate method. This study was carried out in order to evaluate cotton varieties to drought stress and determine the best drought indices measures for increase and improvement of varieties yield in stress and non-stress condition. Also, this study was undertaken to assess the selection criteria for identifying drought tolerance in cotton varieties, so that suitable varieties can be recommended for cultivation in drought prone areas.

\section{Materials and Methods}

The laboratory experiment was carried out in division of Crop Physiology, Agriculture Research Station, Dharwad, India to screen eight cotton varieties viz., ARBH-813, Sahana, DLSa-17, PA-810, DB-1602, SCS1061, CPD-1652, Suvin were used to assess their performance for drought tolerance during 2020. The genotypes were screened for tolerance to different osmotic stress conditions by slanting glass plate technique using different concentrations of Poly ethylene glycol-6000(PEG-6000) at germination stage.

PEG-6000 solutions were prepared with osmotic potentials of $0.0 \mathrm{MPa},-0.05 \mathrm{MPa}$,$0.148 \mathrm{MPa},-0.295 \mathrm{MPa},-0.491 \mathrm{MPa}$ and $0.735 \mathrm{MPa}$ which is equivalent to PEG percent concentrations of $0 \%, 5 \%, 10 \%, 15 \%$,
$20 \%$ and $25 \%$ respectively. The concentrations of PEG-6000 required to obtain these values were determined by using the equation of Michel et al., $\Psi_{\mathrm{s}}=-(1.18 \times 10-$ 2) $\mathrm{C}-(1.18 \times 10-4) \mathrm{C}_{2}+(2.67 \times 10-4) \mathrm{CT}+$ $(8.39 \times 10-7) \quad \mathrm{C}_{2} \mathrm{~T}$ Where, $\Psi_{\mathrm{s}}=$ osmotic potential (bar) $\mathrm{C}=$ concentration $(\mathrm{g} \mathrm{L}-1 \mathrm{PEG}-$ 6000 in water) $\mathrm{T}=$ temperature $\left({ }^{\circ} \mathrm{C}\right)$ As a control, a solution with osmotic potential $\Psi_{\mathrm{S}}=0.0 \mathrm{MPa}(0.0$ bar $)$ was used. The germination percentage, root length and shoot length parameters were recorded from all the germinated seedlings at 12 th and $18^{\text {th }}$ days after imposing the treatments and the mean values are presented in tables.

\section{Slanting glass plate technique methodology}

This method is similar to the routinely used seed germination testing methods using petri plates. But in the present study to allow the roots to grow freely and linearly the glass plate is used in vertical slanting position instead of petri plates in the present study the glass plate having $3 \mathrm{~mm}$ thickness with $25 \mathrm{~cm}$ length and $30 \mathrm{~cm}$ breadth were used. The length and breadth depends on the number of seeds used for the germination study in the laboratory. The glass plates were covered with 560 × $570 \mathrm{~mm}$ fine quality filter paper sheets from bottom to top. Uniform sized good quality delinted seeds were selected from each of 8 different genotypes.

The delinted seeds were initially disinfected with $0.1 \% \mathrm{HgCl}_{2}$ for 5 minutes. Six seeds were kept on top portion of the filter paper/glass plate at $3 \mathrm{~cm}$ spacing. The seeds were covered with a small strip of filter paper. Suitable holding material was used to avoid the fall of seeds in slanting position. Initially little quantity of respective prepared PEG solutions was added on to the small strip of filter paper which helps in adsorption of seeds on to filter paper firmly. Glass plate was inserted in polythene cover. The plate was 
transferred on the supporting wooden block in slanting position. $250 \mathrm{ml}$ of corresponding concentrations $(0 \%, 5 \% 10 \%, 5 \%, 20 \%$ and $25 \%$ ) of PEG-6000 osmotic solutions were added separately into the respective polythene cover carrying separate genotype seeds in slanting plate. The PEG solution moved upward and reached to the seeds by capillary movement through filter paper. Seedlings were allowed to grow under room temperature. Fresh PEG solutions were added in regular intervals of three days to maintain the level of solution. No need of providing aeration to roots, since regularly exchange of fresh PEG solutions was done.

\section{Observations}

Germination (\%) -The seedlings emerged from PEG-6000 solutions were considered as germinated and observation was recorded on $12^{\text {th }}$ and $18^{\text {th }}$ DAS and expressed in percentage. Root length $(\mathrm{cm})-$ Germinated seedling roots in each replication were measured from collar region to the tip of the longest root on $12^{\text {th }}$ and $18^{\text {th }}$ DAS was expressed in $\mathrm{cm}$.

Shoot length $(\mathbf{c m})$ - The shoot length of above selected seedling was measured from collar region to tip of the shoot on $12^{\text {th }}$ and $18^{\text {th }}$ DAS and was expressed in $\mathrm{cm}$.

Root: shoot ratio - The ratio of root length and the shoot length of each seedling selected above was calculated. Observations were recorded on $12^{\text {th }}$ and $18^{\text {th }}$ DAS.

Seedling vigour - Shoot and root length indices were calculated at on $12^{\text {th }}$ and $18^{\text {th }}$ DAS as described by (Abdubaki et al., 1973). Shoot vigour index $=$ Shoot length $x$ germination \% Root length index $=$ root length $\times$ germination $\%$. Seedling vigour index $=$ (root length + shoot length $) \times$ germination $\%$

\section{Results and Discussion}

\section{Germination percentage (\%)}

The PEG concentration and genotypes are differed significantly with respect to germination percentage was presented in (Table 1). Experimental results showed that final germination percent significantly affected by PEG 6000. The final germination per cent decreased by increasing osmotic potential. In distilled water (Control), percentage of seed germination was highest. As the concentration of PEG-6000 increases seed germination is restricted. The seed germination percentage decreased as the PEG 6000 concentration increases from $0 \%$ to $25 \%$. The PEG concentrations, genotypes and their interactions differed significantly with respect to germination percentage. Among the PEG concentrations, control $(0.00$ concentration) recorded significantly higher germination per cent (100), which was significantly differed with $5 \%$ (88.75) and 10 $\%(83.75), 15 \%$ (70), $20 \%(25)$ and in $25 \%$ (0) no germination was observed.

Whereas the genotypes, PA-810 recorded highest (76.66) germination percentage followed CPD-1652, SCS-1061, DB-1602, DLSa-17, Sahana (66.66, 66.66, 61.66, 60, 58.33 respectively). The genotypes such as, ARBH-813 recorded less germination per cent (46.66). Results were conformity with decreased seed germination is due to reduction in imbibitions of water by seeds which leads to a series of metabolic changes, including general reduction in hydrolysis and utilization of the seed reserve. Increase osmotic stress limit the mobilization of reserves in several species damages cellular machinery.

Higher concentration of PEG is the lethal water potential for germination of cotton seeds, hence the germination was ceased. 
Results showed that the seeds of $I$. zollingeriana were able to adapt to drought at the PEG concentration of $20 \%$, despite the salt stress which affected the plant growth (Nadir et al., 2019).

\section{Shoot length $(\mathrm{cm})$}

The shoot length decreased with the increase in PEG-6000 concentrations from $0 \%$ to $20 \%$. The decreased shoot organs helps in reducing transpiration water loss from shoot surfaces. PA-810, CPD-1652, DB-1602 performed well in all PEG-6000 concentrations whereas suvin, ARBH-813 and Sahana recorded lower values (5.63, 5.98 and 7.13 respectively). In Table 2 showed that different PEG concentrations and genotypes differed significantly with respect to shoot length.

The decreased shoot organs helps in reducing transpiration water loss from shoot surfaces. Shoots elongation significantly decreased by concentration of 2-8 $\mathrm{MPa}$ whereas no hypocotyl elongation at concentration of 10 and $12 \mathrm{MPa}$ and shoot elongation completely inhibited (Babu et al., 2014; Toosi et al., 2014). The effect of PEG-6000 was significant for germination percentage and shoot length whereas it was not significant for root length (Srihima et al., 2014).

\section{Root length (cm)}

Root length was increased with the increasing PEG-6000 concentrations up to 10\% of PEG6000 concentrations after that it shown declined in root length in all genotypes. The data on root length $(\mathrm{cm})$ of cotton varieties as influenced by the different concentration of PEG-6000 and their interactions are presented in Table 3. Root length was significantly maximum at $10 \%$, followed by $5 \%$ and control. The root length differed significantly with respect to genotypes. Genotypes, PA810,CPD-1652, DB-1602 (12.72, 12.17 and
$11.88 \mathrm{~cm}$ ) recorded significantly higher root length than genotypes, Suvin, ARBH-813 and Sahana recorded significantly lowest root length $(9.80,9.85,10.50$, respectively). Root length was increased with the increasing PEG-6000 concentrations up to 10\% PEG6000 concentrations it declined thereafter. The increased root length might be due to under water stress the plant partitioned more photosynthates for the growth of roots rather than shoots, helps in absorbing more water from deeper surfaces (Babu et al., 2014)

\section{Root to shoot ratio}

The root to shoot ratio was also differed significantly with respect to different concentrations of PEG-6000, genotypes and their interactions (Table 4). Among the PEG6000 concentrations root to shoot ratio was found maximum in 20 per cent (3.03) which was followed by 10 per cent (1.74) among the genotypes Suvin and ABBH-813 recorded (2.01 and 1.74, respectively) significantly higher root to shoot ratio followed by SCS1061 and DLSa-17. These results are agree with (Murillo-Amador et al., 2002) in cowpea, (Radhouane et al., 2007) in pearl millet and (Toosi et al., 2014) in Brassica juncea they affirmed that a moderate and low osmotic stress (PEG) showed faster radicel growth and Low osmotic stress ( -2 and -4 $\mathrm{MPa}$ ) improves the root length of the seedlings.

Water deficit was induced through polyethylene glycol (PEG-6000), by maintaining two osmotic potentials in water culture medium, i.e. $-0.7 \mathrm{MPa}$ (medium water stress) and $-1.0 \mathrm{MPa}$ (high water stress). After seed germination, drought stress was applied for 8 days. Seedlings shoot and root length and biomasses were restricted with an increase in osmotic deficit (Summiya et al., 2019). 
Table.1 Effect of different concentrations of PEG-6000 on germination (\%) of cotton

\begin{tabular}{|c|c|c|c|c|c|c|c|c|}
\hline \multirow{2}{*}{ Genotype } & \multicolumn{7}{|c|}{ Germination(\%)PEG-6000 Concentrations } \\
\hline & $0 \%$ & $5 \%$ & $10 \%$ & $15 \%$ & $20 \%$ & $25 \%$ & Mean \\
\hline CPD-1652 & 100 & 90 & 90 & 80 & 40 & 0 & 66.66 \\
\hline Sahana & 100 & 80 & 80 & 60 & 20 & 0 & 58.33 \\
\hline PA-810 & 100 & 100 & 90 & 90 & 80 & 0 & 76.66 \\
\hline DLSa-17 & 100 & 100 & 90 & 70 & 0 & 0 & 60.00 \\
\hline ARBH-813 & 100 & 100 & 80 & 0 & 0 & 0 & 46.66 \\
\hline SCS-1061 & 100 & 100 & 90 & 90 & 20 & 0 \\
\hline DB-1602 & 100 & 70 & 80 & 80 & 40 & 0 \\
\hline Suvin & 100 & 70 & 70 & 80 & 0 & 0 \\
\hline Mean & 100 & 88.75 & 83.75 & 70 & 25 & 61.66 \\
\hline
\end{tabular}

Table.2 Effect of different concentrations of PEG-6000 on cotton shoot length $(\mathrm{cm})$ at different growth stages

\begin{tabular}{|c|c|c|c|c|c|c|c|c|c|c|c|c|c|c|}
\hline \multirow[t]{2}{*}{ Genotype } & \multicolumn{7}{|c|}{$\begin{array}{c}12^{\text {th }} \text { day } \\
\text { PEG-6000 Concentrations }\end{array}$} & \multicolumn{7}{|c|}{$\begin{array}{c}18^{\text {th }} \text { day } \\
\text { PEG-6000 Concentrations }\end{array}$} \\
\hline & $0 \%$ & $5 \%$ & $10 \%$ & $15 \%$ & $20 \%$ & $25 \%$ & Mean & $0 \%$ & $5 \%$ & $10 \%$ & $15 \%$ & $20 \%$ & $25 \%$ & Mean \\
\hline CPD-1652 & 12.41 & 11.71 & 9.6 & 9.8 & 2.33 & 0.0 & 7.64 & 13.91 & 12.59 & 12.17 & 11.8 & 4.2 & 0.0 & 9.11 \\
\hline Sahana & 9.2 & 8.9 & 7.1 & 6.9 & 1.5 & 0.0 & 5.60 & 10.3 & 10.1 & 9.9 & 9.5 & 3.0 & 0.0 & 7.13 \\
\hline PA-810 & 13.16 & 11.46 & 9.9 & 10.1 & 2.5 & 0.0 & 7.85 & 14.2 & 13.15 & 12.31 & 11.32 & 4.32 & 0.0 & 9.22 \\
\hline DLSa-17 & 10.8 & 10.2 & 9.0 & 8.5 & 1.8 & 0.0 & 6.72 & 11.9 & 11.3 & 10.8 & 10.7 & 3.9 & 0.0 & 8.10 \\
\hline ARBH-813 & 7.8 & 7.3 & 6.6 & 6.5 & 1.2 & 0.0 & 4.90 & 8.8 & 8.4 & 8.0 & 7.8 & 2.9 & 0.0 & 5.98 \\
\hline SCS-1061 & 9.6 & 9.6 & 8.8 & 8.2 & 1.8 & 0.0 & 6.33 & 10.7 & 10.2 & 10.0 & 9.8 & 3.6 & 0.0 & 7.38 \\
\hline DB-1602 & 10.37 & 10.12 & 9.1 & 8.8 & 2.1 & 0.0 & 6.75 & 12.48 & 12.11 & 11.9 & 11.5 & 4.2 & 0.0 & 8.70 \\
\hline Suvin & 7.3 & 7.1 & 6.3 & 6.1 & 1.0 & 0.0 & 4.63 & 8.1 & 7.9 & 7.8 & 7.3 & 2.7 & 0.0 & 5.63 \\
\hline Mean & 10.08 & 9.55 & 8.30 & 8.11 & 1.78 & 0.00 & & 11.30 & 10.72 & 10.36 & 9.97 & 3.60 & 0.00 & \\
\hline
\end{tabular}


Table.3 Effect of different concentrations of PEG-6000 on cotton root length $(\mathrm{cm})$ at different growth stages

\begin{tabular}{|c|c|c|c|c|c|c|c|c|c|c|c|c|c|c|}
\hline \multirow[t]{2}{*}{ Genotype } & \multicolumn{7}{|c|}{$\begin{array}{c}12^{\text {th }} \text { day } \\
\text { PEG-6000 Concentrations }\end{array}$} & \multicolumn{7}{|c|}{$\begin{array}{c}18^{\text {th }} \text { day } \\
\text { PEG-6000 Concentrations }\end{array}$} \\
\hline & $0 \%$ & $5 \%$ & $10 \%$ & $15 \%$ & $20 \%$ & $25 \%$ & Mean & $0 \%$ & $5 \%$ & $10 \%$ & $15 \%$ & $20 \%$ & $25 \%$ & Mean \\
\hline CPD-1652 & 8.5 & 10.2 & 16.3 & 9.5 & 5.9 & 0.5 & 8.48 & 13 & 15.1 & 18.7 & 14.4 & 10.3 & 1.5 & 12.17 \\
\hline Sahana & 7.8 & 8.7 & 13.1 & 8.4 & 4.8 & 0.0 & 7.13 & 11.7 & 13.8 & 17.3 & 13.1 & 7.1 & 0.0 & 10.50 \\
\hline PA-810 & 8.8 & 11.6 & 16.8 & 9.7 & 6.1 & 0.6 & 8.93 & 13.2 & 15.3 & 19.5 & 15 & 11.1 & 2.2 & 12.72 \\
\hline DLSa-17 & 8.2 & 9.3 & 13.9 & 9.2 & 5.4 & 0.0 & 7.67 & 12.5 & 14.3 & 17.9 & 13.8 & 9.7 & 1.2 & 11.57 \\
\hline ARBH-813 & 7.5 & 8.7 & 12.7 & 8.2 & 4.4 & 0.2 & 6.95 & 11.3 & 12.5 & 16.1 & 12.3 & 6.9 & 0.0 & 9.85 \\
\hline SCS-1061 & 8.0 & 9.1 & 13.7 & 9.1 & 5.0 & 0.0 & 7.48 & 12.1 & 14.1 & 17.7 & 13.8 & 8.6 & 0.0 & 11.05 \\
\hline DB-1602 & 8.3 & 9.7 & 15.2 & 9.4 & 5.7 & 0.4 & 8.12 & 12.8 & 14.7 & 18.2 & 14.1 & 10.2 & 1.3 & 11.88 \\
\hline Suvin & 7.0 & 8.1 & 12.8 & 8.0 & 3.9 & 0.0 & 6.63 & 9.9 & 11.4 & 15.3 & 11.9 & 10.3 & 0.0 & 9.80 \\
\hline Mean & 8.01 & 9.43 & 14.31 & 8.94 & 5.15 & 0.21 & & 12.06 & 13.90 & 17.59 & 13.55 & 9.28 & 0.78 & \\
\hline
\end{tabular}

Table.4 Effect of different concentrations of PEG-6000 on cotton root to shoot ratio at different growth stages

\begin{tabular}{|c|c|c|c|c|c|c|c|c|c|c|c|c|c|c|}
\hline \multirow[t]{2}{*}{ Genotype } & \multicolumn{7}{|c|}{$\begin{array}{c}12^{\text {th }} \text { day } \\
\text { PEG-6000 Concentrations }\end{array}$} & \multicolumn{7}{|c|}{$\begin{array}{c}18^{\text {th }} \text { day } \\
\text { PEG-6000 Concentrations }\end{array}$} \\
\hline & $0 \%$ & $5 \%$ & $10 \%$ & $15 \%$ & $20 \%$ & $25 \%$ & Mean & $0 \%$ & $5 \%$ & $10 \%$ & $15 \%$ & $20 \%$ & $25 \%$ & Mean \\
\hline CPD-1652 & 0.68 & 0.87 & 1.69 & 0.96 & 2.5 & 0.0 & 1.12 & 0.93 & 1.19 & 1.53 & 1.22 & 2.45 & 0.0 & 1.46 \\
\hline Sahana & 0.84 & 0.97 & 1.84 & 1.21 & 3.2 & 0.0 & 1.34 & 1.13 & 1.36 & 1.74 & 1.37 & 2.36 & 0.0 & 1.59 \\
\hline PA-810 & 0.66 & 1.01 & 1.69 & 0.96 & 2.4 & 0.0 & 1.13 & 0.92 & 1.16 & 1.58 & 1.32 & 2.56 & 0.0 & 1.51 \\
\hline DLSa-17 & 0.75 & 1.13 & 1.54 & 1.08 & 3.0 & 0.0 & 1.25 & 1.05 & 1.26 & 1.65 & 1.28 & 2.48 & 0.0 & 1.54 \\
\hline ARBH-813 & 0.96 & 1.19 & 1.92 & 1.26 & 3.7 & 0.0 & 1.50 & 1.28 & 1.48 & 2.01 & 1.57 & 2.37 & 0.0 & 1.74 \\
\hline SCS-1061 & 0.83 & 0.94 & 1.55 & 1.1 & 2.8 & 0.0 & 1.20 & 1.13 & 1.38 & 1.77 & 1.4 & 2.38 & 0.0 & 1.61 \\
\hline DB-1602 & 0.8 & 0.95 & 1.67 & 1.06 & 2.7 & 0.0 & 1.20 & 1.02 & 1.21 & 1.52 & 1.22 & 2.42 & 0.0 & 1.48 \\
\hline Suvin & 0.95 & 1.14 & 2.03 & 1.31 & 3.9 & 0.0 & 1.56 & 1.22 & 1.44 & 1.96 & 1.63 & 3.81 & 0.0 & 2.01 \\
\hline Mean & 0.81 & 1.03 & 1.74 & 1.12 & 3.03 & 0.00 & & 1.09 & 1.31 & 1.72 & 1.38 & 2.60 & 0.00 & \\
\hline
\end{tabular}


Table.5 Effect of different concentrations of PEG-6000 on cotton shoot vigour index at different growth stages

\begin{tabular}{|c|c|c|c|c|c|c|c|c|c|c|c|c|c|c|}
\hline \multirow[t]{2}{*}{ Genotype } & \multicolumn{7}{|c|}{$\begin{array}{c}12^{\text {th }} \text { day } \\
\text { PEG-6000 Concentrations }\end{array}$} & \multicolumn{7}{|c|}{$\begin{array}{c}18^{\text {th }} \text { day } \\
\text { PEG-6000 Concentrations }\end{array}$} \\
\hline & $0 \%$ & $5 \%$ & $10 \%$ & $15 \%$ & $20 \%$ & $25 \%$ & Mean & $0 \%$ & $5 \%$ & $10 \%$ & $15 \%$ & $20 \%$ & $25 \%$ & Mean \\
\hline CPD-1652 & 1241 & 1053.9 & 864 & 784 & 93.2 & 0.0 & 672.68 & 1391 & 1133 & 1095 & 944 & 168 & 0.0 & 788.50 \\
\hline Sahana & 920 & 712 & 568 & 414 & 30.0 & 0.0 & 440.67 & 1030 & 808 & 792 & 570 & 60 & 0.0 & 543.33 \\
\hline PA-810 & 1316 & 1146 & 891 & 909 & 200.0 & 0.0 & 743.67 & 1420 & 1315 & 1107 & 1018 & 345.6 & 0.0 & 867.60 \\
\hline DLSa-17 & 1080 & 1020 & 810 & 595 & 0.0 & 0.0 & 584.17 & 1190 & 1130 & 1080 & 749 & 0.0 & 0.0 & 691.50 \\
\hline ARBH-813 & 780 & 130 & 528 & 0.0 & 0.0 & 0.0 & 239.67 & 880 & 840 & 800 & 0.0 & 0.0 & 0.0 & 420.00 \\
\hline SCS-1061 & 960 & 960 & 792 & 738 & 36.0 & 0.0 & 581.00 & 1070 & 1020 & 1000 & 882 & 72 & 0.0 & 674.00 \\
\hline DB-1602 & 1037 & 708.4 & 728 & 704 & 84.0 & 0.0 & 543.57 & 1248 & 847.7 & 833 & 920 & 168 & 0.0 & 669.45 \\
\hline Suvin & 730 & 497 & 441 & 488 & 0.0 & 0.0 & 359.33 & 810 & 553 & 546 & 584 & 0.0 & 0.0 & 415.50 \\
\hline Mean & 1008.00 & 778.41 & 702.75 & 579.00 & 59.87 & 0.00 & & 1129.88 & 955.84 & 958.14 & 708.38 & 101.70 & 0.0 & \\
\hline
\end{tabular}

Table.6 Effect of different concentrations of PEG-6000 on cotton root length index at different growth stages

\begin{tabular}{|c|c|c|c|c|c|c|c|c|c|c|c|c|c|c|}
\hline \multirow[t]{2}{*}{ Genotype } & \multicolumn{7}{|c|}{$\begin{array}{c}12^{\text {th }} \text { day } \\
\text { PEG-6000 Concentrations }\end{array}$} & \multicolumn{7}{|c|}{$\begin{array}{c}18^{\text {th }} \text { day } \\
\text { PEG-6000 Concentrations }\end{array}$} \\
\hline & $0 \%$ & $5 \%$ & $10 \%$ & $15 \%$ & $20 \%$ & $25 \%$ & Mean & $0 \%$ & $5 \%$ & $10 \%$ & $15 \%$ & $20 \%$ & $25 \%$ & Mean \\
\hline CPD-1652 & 850 & 918 & 1467 & 760 & 236.0 & 0.0 & 705.17 & 1300 & 1359 & 1683 & 1152 & 412 & 0.0 & 984.33 \\
\hline Sahana & 780 & 696 & 1048 & 504 & 96.0 & 0.0 & 520.67 & 1170 & 1104 & 1384 & 786 & 142 & 0.0 & 764.33 \\
\hline PA-810 & 880 & 1160 & 1512 & 873 & 488.0 & 0.0 & 818.83 & 1320 & 1530 & 1755 & 1350 & 888 & 0.0 & 1140.50 \\
\hline DLSa-17 & 820 & 930 & 1251 & 644 & 0.0 & 0.0 & 607.50 & 1250 & 1430 & 1611 & 966 & 0.0 & 0.0 & 876.17 \\
\hline ARBH-813 & 750 & 870 & 1016 & 0.0 & 0.0 & 0.0 & 439.33 & 1130 & 1250 & 1288 & 0.0 & 0.0 & 0.0 & 611.33 \\
\hline SCS-1061 & 800 & 910 & 1233 & 819 & 100.0 & 0.0 & 643.67 & 1210 & 1410 & 1593 & 1242 & 172 & 0.0 & 937.83 \\
\hline DB-1602 & 830 & 679 & 1216 & 752 & 228.0 & 0.0 & 617.50 & 1280 & 1029 & 1456 & 1128 & 408 & 0.0 & 883.50 \\
\hline Suvin & 700 & 567 & 896 & 640 & 0.0 & 0.0 & 467.17 & 9900 & 798 & 1071 & 952 & 0.0 & 0.0 & 2120.17 \\
\hline Mean & 801.25 & 841.25 & 1204.88 & 624.00 & 143.50 & 0.00 & & 2320.00 & 1238.75 & 1480.13 & 947.00 & 252.75 & 0.0 & \\
\hline
\end{tabular}




\section{Indices}

Seedling indices like shoot vigor index, and root length index are calculated at $18^{\text {th }}$ day of different PEG concentrations as per the standard formulae by using germination per cent, shoot length and root length differed significantly with respect to PEG concentrations, genotypes and their interactions.

\section{Shoot vigor index (SVI)}

It could be seen from the Table 5 that PEG concentrations, genotypes and their interactions differed significantly at 18 th day after sowing with respect to Shoot vigor index. Among the PEG concentration, significantly higher shoot vigor index was recorded in control (1129.88) than 5 per cent and 10 per cent (955.84 and 958.14, respectively). The genotype, PA-810 was recorded (867.60) significantly higher shoot vigor index which was followed by CPD1652 (788.50), DB-1602 (669.45) Whereas, the genotype Suvin (415.50) recorded significantly less seedling vigor index followed by ARBH-813(420.00).

\section{Root length index}

The results obtained with respect to Root length index at 18th day Table 6, indicated that PEG concentrations, genotypes and their interaction differed significantly. Among the PEG concentration, $0 \%$ recorded significantly higher root vigor index (2320.00) followed by $10 \%$ (1480.13). The genotype, Suvin was recorded (2120.17) significantly higher root length index which was followed by PA-810, CPD-1652 and SC-1061(1140.50, 984.33 and 937.83 respectively). Whereas, the genotype ARBH-813 (611.33) recorded significantly less root length index followed by Sahana and DLSa-17(764.33 and 876.17 respectively).
It is concluded that the laboratory experiment was to study the germination studies of 8 cotton varieties were evaluated to identify tolerant genotypes under different osmotic potential by using PEG-6000 viz., 0\%, 5\%, $10 \%, 15 \%, 20 \%$ and $25 \%$ in a slanting plate technique was to identify tolerant varieties. Among the varieties, the germination percentage, shoot length, Root length and seedling vigour were recorded at different time intervals. All these observations indicate PA-810, CPD-1652, DB-1602 and DLSa-17 were found to be growing well upto $20 \%$ PEG-6000 solution. Also found that at 25\% PEG-6000 concentration none of the genotypes were germinated, it showed that 25\% PEG-6000 is lethal to cotton plants.

\section{References}

Cotton corporation of India, 2019-20 (Provisionsl).

Babu, A.G., Patil, B.C., Pawar, K.N., 2014. Evaluation of cotton genotypes for drought tolerance using PEG-6000 water stress by slanting glass plate technique. The Bioscan 9(2), 1419-1424.

Fanti, S. C. and Perez, S. C. J. G. A., 2004. Water stress and accelerated aging effects on the viability of osmoconditioned Chorisia speciosa seeds. Pesquisa Agropecuária Brasileira, 38: 537-543.

Fernandez, C. J. and Mariaelena.,1998.Effects of drought on growth and photosynthetic capacity of cotton. Internet Association for Biomedical Sciences, pp. 98: 2-6.

FICCI,2012.Cotton 2020 Road Map for Sustainable Production. Agriculture Division. Federation house, Tansen Marg, New Delhi 110001, India.

Michel, E. B. and Merrill, R. K., 1973.The Osmotic Potential of Polyethylene Glycol 60001. Plant Physiol., 51: 914- 
916.

Murillo-Amador, B., Lopez-Aguilar, R., Kaya, C., Larrinaga-Mayoral, J., FloresHernandez, A. 2002. Comparative effect of $\mathrm{NaCl}$ and PEG on germination emergence and seedling growth of cowpea. J. Agron. Crop Sci., 188: 235247.

M Nadir, I Ansyar, P I Khaerani and Syamsuddin., 2019. Effect of various polyethylene glycol concentrations on the growth of seedlings of Indigofera zollingeriana. IOP Conf. Series: Earth and Environmental Science 343.

Radhouane, L.,2007. Response of Tunisian autochthonous pearl millet (Pennisetum glaucum (L.) R. Br.) to drought stress induced by polyethylene glycol (PEG) 6000. Afr. J. Biotechnol., 6: 1102-1105.

Larcher, W., 2000. Plant Ecophysiology. RIMA, São Carlos, SP, Brazil. 5: 31 p. (in Portuguese)

Srihima Gampala,Vikram Jeet Singh, S.K.
Chakraborti., K.P. Vishwajith and G.R. Manjunath., 2014. Genotypic differences against poly ethylene glycol (PEG) simulated drought stress in rice.

Summiya Faisal, S. M. Mujtaba, Asma and Wajid Mahboob., 2019. Polyethylene Glycol Mediated Osmotic Stress Impacts on Growth and Biochemical Aspects of Wheat (Triticum aestivum L.) Journal of Crop Science and Biotechnology volume 22, 213-223.

Tonin, G.A., Carvalho, N.M., Kronka, S.N., Ferraudo, A.S., 2000. Culture systems, velvet bean and mineral fertilization influence on maize seeds physiological quality. Revista Brasileira de Sementes 22, 276-279.

Yu, X.G., Sun, J.S., Xiao, J.F., 1999. A study on drought indices and lower limit of suitable soil moisture of cotton. Acta Gossypii Sinica 11(1), 35-38.

\section{How to cite this article:}

Pawar, K. N. and Veena, V. B. 2020. Evaluation of Cotton Genotypes for Drought Tolerance using PEG-6000 Water Stress by Slanting Glass Plate Technique. Int.J.Curr.Microbiol.App.Sci. 9(11): 3203-3212. doi: https://doi.org/10.20546/ijcmas.2020.911.386 